\title{
LA DIMENSIÓN FEMENINA DE DIOS PADRE
}

Agustina Serrano ${ }^{1}$

\section{A. La Revelación y el Ocultamiento de Dios.}

\section{El conocimiento y el lenguaje sobre Dios.}

El misterio divino se manifiesta en nuestro mundo, en la naturaleza, en el hombre mismo y en la historia. El misterio del hombre, de su mundo y de su historia se transciende a sí mismo e implica también a Dios².

A Dios lo conocemos fundamentalmente en nuestra realidad humana, histórica, concreta, y ésta es una manera limitada de conocer ya que Dios es transcendente. De Dios tenemos experiencia, vivencia y nos sabemos existiendo en su amor, y también sabemos que Dios se ubica más allá de cualquier modo de expresarlo. La esencia del misterio divino queda oculta, lo infinito es solo atisbo.

El hablar sobre Dios se hace desde la propia experiencia de fe; desde un encuentro que cambió nuestra vida. Por ello toda la reflexión ha de entenderse en un clima comunicativo, en referencia al Tú de Dios. Para acceder a esta realidad infinita, ella debe abrirse, manifestarse a nosotros.

Tratar de conocer y hablar del Misterio inefable, el radicalmente Otro, con palabras finitas y cortas para expresar la realidad de Dios es un atrevimiento y en un determinado momento, tal vez, es mejor callar para contemplarlo y amarlo a Él.

Rescatar el valor del lenguaje simbólico en cuanto que es capaz de comunicar la verdad. Podemos decir que "Dios es amor" $(1 \mathrm{Jn} 4,8)$ y más que amor, es desbordamiento de amor; y continuar afirmando que "Dios es Abbá" (Jn 2,21-22) y más que Abbá, es superabundancia de mater-paternidad.

Todo lo que sigue es producto de una invitación a ser "narradora" de la parábola sobre el Dios que es Amor, que es Abbá. Sabiendo siempre que vamos a aplicar a Dios lo más plenamente humano, dejando atrás toda connotación limitante y elevándonos sobre todo lo que no es Dios, $\mathrm{y}$ aun así asumir que no podemos conocer

\footnotetext{
1 Ponencia presentada en el V Coloquio de Teología "Dios como Padre. Perspectivas para la evangelización", organizado por el Instituto de Estudios Teológicos de la Universidad Católica de Temuco, en octubre de 1999. "¿Cómo hablar de Dios a los jóvenes?": Actas Teológicas 2 (1998), 37-58.
} 
a Dios en toda su hondura porque la "similitud de nuestras afirmaciones con la realidad va unida a una mayor disimilitud" .

Al lanzarnos a hablar sobre Dios lo primero que detectamos es una pluralidad amplia que hay que aceptar. Esto se debe a la conciencia del propio límite del sujeto que descubre que hay muchas maneras de acceder a la realidad de Dlos y se debe, sobre todo, a la realidad transcendente del Otro, de quien queremos atisbar algo de su ser.

Hay un doble movimiento: el Misterio se comunica a través de realidades limitadas y entendibles para el ser humano, y toda respuesta a ese Misterio es siempre ambigua y parcial.

\section{La explicitación del dato revelado}

Explicar el significado de la Palabra (dato revelado) es lo que pretende la teología y esto para que el mensaje siga siendo relevante y se pueda transmitir la fe en el Dios del Amor.

Para acceder a Dios el ser humano (varón-mujer; cuerpo-espíritu; individuocomunidad) es una mediación muy importante. El ser humano es un atisbo del amor divino ${ }^{4}$ que se configura dando respuesta a las tres interrogantes fundamentales de la persona (qué es el ser humano, quién es el ser humano y cómo es el ser humano). Las respuestas no son totales ni definitivas y se van tejiendo en el diario vivir.

Pero además Dios mismo habla y dice su Palabra, su proyecto, su Misterio, su designio sobre sí mismo y sobre el ser humano. Este ser humano va desvelando (y otras veces ocultando) el proyecto de Dios con los medios a su alcance. Unas veces cuenta historias, otras cuentos; hace poesía, pinta, esculpe, etc. Todos los medios tratan de señalar el camino por el que cada uno, en comunión con otros, ha de adentrarse para descubrir su respuesta a esa llamada de Dios al Amor, a la misericordia y a la gratuidad.

Veamos ahora qué y cómo decir de Dios de manera que cada vez nos sumerjamos más en su Amor. Lo primero que podemos constatar es su ser paradójico. Nuestro Dios es:

口 "escondido y revelado" manifestado en Jesucristo quien nos da el ROSTRO de Dios;

口 "presente y libre" presencializado en el Espíritu Santo quien nos acompaña a su manera, no lo dominamos;

"personal y universal" mío y nuestro, que nos hace hijos y hermanos;

"tierno y fuerte", sufre, está por la vida, gratuito, para siempre, etc.

lb., 143. Lo mismo afirma L.M. ARMENDÁRIZ "El Padre Materno", Estudios Eclesiásticos 58 (1983) 254. La diferencia entre Dios y su creatura es siempre mayor que la semejanza, asi to afirma el Concilio Lateranense IV, Dz 432, esto a la vez que evita nivelar a Dios y al hombre posibilita establecer una legítima relación entre ellos. 
Y además todo lo que podamos aplicarle, pero acotando que DIOS ES SIEMPRE MAYOR.

El cómo decir esto es otro de los elementos a tener en cuenta. Se trata de hablar a Dios y de Dios y para ello, como mejor nos vamos a entender, casi por encima de las palabras, va a ser si entramos en un "clima comunicativo". En este ambiente en el que "hablamos con Dios" aceptando la pluralidad de modos y estilos de vida en esta aventura de vivir la fe. Como mejor nos vamos a comunicar es si tratamos que lo dicho nos evoque experiencia personal, nos provoque cercanía a Dios y nos convoque a entrar en su Misterio.

Dios está más allá y más acá de lo que podamos decir, por ello se trata de intentar que las palabras creen espacio interior para la acogida.

\section{Reflexiones sobre Dios.}

\section{a) El Dios escondido y revelado.}

Lo divino debe entenderse en categorías de relación armónica y dinámica entre polaridades; es empobrecedor aplicar un solo nombre, pues Dios es presente y futuro, revelado y oculto, sufridor y consolador, madre y padre, poderoso e impotente, omnipotente y bueno ${ }^{5}$.

Un solo término y además excluyente va contra el mismo Dios. Es un modo de querer dominarlo y reducirlo. Dios libre se nombra a sí mismo como: Yo soy el que estaba, yo soy el que estoy y sobre todo yo soy el que estaré presente, absolutamente y a mi manera ${ }^{6}$. Es una promesa de Dios de estar presente activamente junto a su pueblo, de una manera imprevisible y no verificable, su estar es libre y absolutamente cierto. "Esta autodefinición histórica de Dios se encuentra también en otros pasajes de la Biblia: Dios es el primero y el último (Is 41,$4 ; 44,6 ; 48,12 ;$ Ap 1,17$)^{m 7}$.

Se trata de evocar realidades que nos aproximen a la experiencia del misterio de Dios, que nos acerquen al Dios que se autocomunica. "El misterio divino /.../ es un misterio hablante que interpela al hombre y al que nosotros podemos dirigir la palabra. Dios no suprime su misterio en el acto de revelación; no lo descifra. / .../ La revelación consiste más bien en que Dios manifiesta su misterio oculto. /.../La reve-

5 Cfr L.M. ARMENDÁRIZ "Creo en Dios Todopoderoso. Tres formas de la omnipotencia divina": Sal Terrae, 1012 (1998) 363-374. La omnipotencia de Dios queda en entredicho ante la realidad del mal y del dolor y sufrimiento, sobre todo, del inocente, y asi se cuestiona la bondad de Dios. El autor plantea la omnipotencia como con-descendencia del creador, como com-pasión del Amor y como con-sumadora del final.

W. KASPER, 177. Esto se mantiene en la segunda revelación del nombre en Ex 33,18-23: "hago gracia a quien hago gracia [ani hanan 'aser hanan = aupar al niño al pecho] y tengo misericordia con quien tengo misericordia [ani rahûm 'aser rahûm = estremecer las entrañas]" y Ex 34,6-9 "Dios misericordioso y clemente [hanum rahum], .... y rico en amor y fidelidad [hesed we emet] ...". 
lación es, pues, revelación del Dios oculto"8.

La autorrevelación de Dios es a la vez ocultamiento. Esta polaridad revelaciónocultamiento de Dios también se da en Jesucristo, cumbre de la revelación; El es la imagen (Cfr 2 Cor 4,4; Col 1,15; Hb 1,3); El es el Dios con rostro humano (Cfr Jn 14,9).

"La autorrevelación de Dios en Jesucristo ocultó a Dios -como expuso Lutero en su theologia crucis- sub contrario, bajo su contrario. Esta presencia oculta de Dios en Jesucristo continúa en cierto modo en los hermanos de Jesucristo, sobre todo en los pobres, humildes, enfermos, perseguidos y moribundos (Mt 25, 31-46). El carácter oculto de Dios no significa, pues, a nivel teológico ese Deus absconditus lejano y transcendente, sino el Deus revelatus presente bajo la alienación del mundo. /.../. El poder en la impotencia humana, la plenitud en el vacío, la vida en la muerte $^{\text {"g }}$.

Recuperar la experiencia de lo cotidiano, la pasividad y la actividad; atrevernos a formular la presencia y la ausencia de Dios; la fuente y la noche en expresiones de San Juan de la Cruz. La mística es una buena escuela, ayuda a experimentar que la nada impotente de la vida desfavorecida nos acerca al amor y ahí nada nos podrá separar de Dios porque su amor al poseernos, nos desborda ${ }^{10}$.

\section{b) Mensaje sobre Dios.}

La palabra padre es una de esas palabras ancestrales de la historia cultural y religiosa de la humanidad. Hoy se pone en entredicho desde la sociología, la psicología, el movimiento de liberación de la mujer, lo que nos lleva a profundizar el fundamento que da origen y medida a todo.

La Biblia es reservada a la hora de llamar a Dios "padre"; se dice el "Dios de nuestros padres"11. En el Antiguo Testamento hay unos 20 pasajes que designa a Dios como padre ${ }^{12}$.

El Dios que se revela habla el lenguaje humano, muestra la paternidad de Dios unida a la filiación de Israel y realizada en la historia, sobre todo:

8

9 lb., 151.

lb., 152.

Cfrr Rm 8, 35.

Cfr P. RICOEUR, "La figura del padre: de la imagen de la fantasía al simbolo", en Hermenéutica y psicoanálisis. El conflicto de las interpretaciones , Buenos Aires 1975, 106. "Esta revelación del nombre-afirma Paul Ricoeur-significa la disolución de todas las representaciones antropomórficas, de todas las formas y figuras $y$, por tanto, tamblén la figura del padre. El Nombre está en contra del Idolo". La revelación del nombre no transmite ninguna teologia del padre. 
Vinculada a la idea de futuro y desde la esperanza de lo nuevo ${ }^{13}$. Con rasgos femeninos y maternales ${ }^{14}$.

En el N.T. Jesús vincula la llegada del Reino con su persona y con la del Padre (170 veces la palabra). Jesucristo es el rostro de Dios. El Dios de Jesucristo es pura gratuidad, autocomunicación amorosa y misericordiosa, es libertad y dignidad del ser humano ${ }^{15}$.

La imagen de Padre en Jesús puede interpretarse en línea profética, a partir del Reino de Dios, el Padre que está en los cielos es al que pedimos que venga su reino. Este Dios Padre es quien libera, da de comer, sana, provoca relaciones de recibir y dar graciosamente, darse a si mismo (Cfr Mt 7, 9-11: "¿Acaso si alguno de vosotros su hijo le pide pan le da una piedra?"); este Dios Padre se comporta con los hijos dándoles, alimentándoles, regalándoles ${ }^{16}$.

En el cuarto evangelio queda patente la gran novedad que supone en el Nuevo

Cfr W. KASPER, 167. "La expectativa de lo nuevo se funda en definitiva en el amor misericordioso de Dios (Os 11,9; Is 63,16; Jr 31,20). "Como un padre siente cariño por sus hijos, siente Yahvé cariño por sus fieles" (Sal 103,13). También D. SÖLLE, Reflexiones sobre Dios, Herder, Barcelona 1996, cap 3, afirma que en los profetas Oseas, Jeremias y en el Tritoisaías y siempre en el contexto de futuro, entendido proféticamente, de una nueva creación (Cfr Jr 3, 19 "Yo habia dicho: 'Si, te tendré como a un hijo y te daré una tierra espléndida, flor de las heredades de las naciones'. Y añadi: 'Padre me llamaréis y de mi seguimiento no os volveréis'"). Se trata de la nueva creación, no del origen. Reconocer al padre es buscar el futuro reino, en el que "la justicia y la paz se besan" (Salmo 85,11).

Cfr W. KASPER, 168. Cita a Is 66,13 , "Como uno a quien su madre le consuela, asi yo os consolaré (y por Jerusalén seréis consolados)". En un artículo de M.C. BINGEMER, "La Trinidad a partir de la perspectiva de la mujer", en El rostro femenino de la teología, Editorial DEI, Costa Rica 1986, 143, da las siguientes citas: Is 49,15-16, "¿Acaso olvida una mujer a su niño de pecho, sin compadecerse del hijo de sus entrañas? Pues aunque ésas llegasen a olvidar, yo no te olvido. Miralo, en las palmas de mis manos te tengo tatuada, tus muros están ante mi perpetuamente. Is 42,14 "Estaba mudo desde mucho ha, había ensordecido, me había reprimido. Como parturienta grito, resoplo y jadeo entrecortadamente". Jr 31,20, "¿Es un hijo tan caro para mi Efraim, o niño tan mimado, que tras haberme dado tanto que hablar, tenga que recordarlo todavia?. Pues, en efecto, se han conmovido mis entrañas por él; ternura hacia él no ha de faltarme -oráculo de Yahveh-". También rescata estos elementos R. RADFORD RUETHER, "EI aspecto femenino de Dios. Un problema de la vida religiosa contemporánea": Concilium 163 (1981), 396ss. Esta autora afirma que hay algunos casos en que se da de Dios una imagen femenina y es para describir "la fidelidad de Dios a Israel y el dolor que sufre a causa de Israel". La imagen femenina aparece también en los sapienciales. La Sabiduría es descrita como hija de Dios, como esposa del alma, en relación con Salomón $($ Sab 8,2.9). Además de la Sabiduria está la imagen femenina de la shekinah que es imagen de la presencia mediadora y reconciliadora de Dios y su pueblo. "El exilio que aleja a Israel de su tierra se considera en ültima instancia como un exilio que lo aleja de Dios, como un divorcio entre los "aspectos" masculino y femenino de Dios", p. 397-398. L.M. ARMENDÁRIZ "EI Padre Materno" 258-259 y 261 notas 32-34, "¿Qué más materno que el poema de Dios en Oseas (Cfr Os $11,1.4 .8)$ ? y ¿qué más femeninamente enternecedor que la promesa de Dios en Isaías (Is 66,13$)$ ?". Y refiriéndose a la Sabiduría la califica de "la confidente del Saber divino y la educadora de los hombres (Sab 8,4; 9,9ss; Eclo 14,22ss; 15,2ss). Un rostro femenino acompañaría así al creador en su trono y endulzaria aún más sus rasgos paternos".

Cfr Jeremias, J., "Abbá...", 37ss; Cfr W. Kasper, 168-169. Conocer al Padre desde el Hijo, Mt 11,27: "... al Padre no lo conoce más que el Hijo..."; Cfr Lc 15, 1ss; 11,9; Mt 7,7.

Cfr J. MOLTMANN, "El Padre maternal. Patripasianismo trinitario y patriarcalismo teológico": Concilium 163 (1981), 381. 
Testamento el revelar a Dios como Padre, éste sería el nombre más auténtico del Dios de Jesucristo ${ }^{17}$. En San Juan, Jesucristo es el revelador y la revelación del Padre, tanto en el prólogo (Jn 1, 18: "A Dios nadie lo ha visto jamás; el Hijo único, Dios que está hacia el seno del Padre, ése lo ha revelado") como en los discursos de revelación a lo largo del evangelio. Por eso el revelador habla con autoridad única del Dios que es Amor ${ }^{18}$.

En San Pablo, Jesucristo es el Hijo que nos hace hijos/as ( $R m$ 8,15; Gal 4,6) que nos hace libres en el amor y en el servicio. Pablo en sus escritos presenta una peculiar experiencia de su relación con Dios, a quien se refiere como "mi Dios"19.

A lo largo de la historia se ha ido adaptando el lenguaje a los oyentes (en el siglo Il los apologetas hablaban a paganos), hoy es un reto expresarlo en fórmulas nuevas que acerquen el mensaje al hombre del tercer milenio. Los rasgos tomados de la familia, imágenes familiares, para referirse a Dios como madre y/o padre nos vinculan con la naturaleza y la familia humana, y nos capacitan para confiar en la vida y en la muerte.

Estas imágenes parentales (la femenina y la masculina) son una analogía limitada para Dios. Por ello hemos de caminar hacia una imagen más completa. El Dios que se nos muestra con rasgos a la vez masculino y femenino nos hace dirigir la mirada hacia una nueva humanidad aún por realizar. En esta imagen más amplia de Dios tratamos de dar nuevo contenido a la visión de la humanidad mesiánica que ya no es "ni varón ni mujer, judío o griego, esclavo o libre" (Gál 3,28$)$, en que Dios "ha derribado el muro de la hostilidad" (Ef 2,14) ${ }^{20}$.

Mientras tanto nos quedamos pensando en las palabras de González Faus al prologar un libro del profesor Bentué: "Algunos libros bíblicos (como Job, el de Jonás y algunas páginas de San Pablo) tienen el curioso valor de ser 'herejías' que han acabado convirtiéndose en 'palabra de Dios'. Es una consecuencia de que la manifestación de Dios sea histórica, y Su verdad vaya adaptándose pedagógicamente a

Cfr M.A. FERRANDO, "Dios Padre en el evangelio según San Juan", Anales de la Facultad de Teología, Pontificia Universidad Católica Chile, Santiago 47 (1996). Es en el evangelio de Juan donde los primeros cristianos dan a Dios el nombre de Padre.

H.U. VON BALTHASAR, "Dios es su propio exégeta", Communio (Madrid) 1 (1986), 9. "En primer lugar por la encarnación y la vida humana del Hijo. /.../ Con sus actitudes enteramente humanas Jesús presenta el corazón sensible del Padre. /.../ Jesús en su naturaleza humana no maniflesta tanto su propia naturaleza divina cuanto la del Padre, del que es continua referencia como hombre y como Dios". Dicho de otra manera el Hijo "ha expuesto', interpretado en figura humana al Padre, a quien nadie ha visto $(\operatorname{In} 1,18)$. Como Palabra hecha carne ha revestido lo Inefable con categorias humanas, pero de suerte que el Dios esencialmente incomprensible destella rompiendo todos los conceptos y definiciones.

Cfr B. VILLEGAS, "El Dios de Pablo. Alcance de "mi Dios" en sus cartas". Teologia y Vida 39 (1998) 150-154. Los textos en los que Pablo dice "mi Dios": Rm 1,8; 1Cor 1,4; 2Cor 12,21 (especialmente valioso); Fip 1,3; 4,19; FIm 4; 1 Tes 2,2; 3,9, p. 150

Cfr R. RUETHER, 398 y 403. En la historia de la teologla se ha nombrado a Dios con términos relacionados con la naturaleza. También se puede enlazar con la tradición mistica; "fuente de todos los bienes", "viento vivo", "agua de la vida", "luz". Se trata de expresar que es fondo, hondura, profundidad. Son símbolos maternos de unión que llega a la armonfa con el Viviente. 
la evolución del ser humano: en un momento dado se traspasa un umbral, y el hombre comprende mejor algo que Dios estaba queriéndole decir desde siempre"21.

\section{B. LA DIMENSIÓN FEMENINA.}

Partamos de la siguiente afirmación: “Fe es aquella manera de vivir y de pensar por la cual se relacionan con Dios todas las cosas de este mundo y de la experiencia humana. Todo se ve, se interpreta y se vive a la luz suprema de Dios"22.

Si queremos detectar, también ${ }^{23}$, la dimensión femenina en Dios, asumiendo el respeto y el valor de toda la identidad de lo humano (masculino y femenino), la autonomia y la reciprocidad, la solidaridad y la fraternidad, podemos acercarnos desde la experiencia y hacernos algunas preguntas: ¿cómo lo femenino revela a Dios?, ¿cómo Dios se revela en lo femenino? O dicho de otro modo: ¿qué rostro quiso mostrarnos Dios mediante lo femenino?, ¿cómo lo femenino nos lleva a Dios?

Se están haciendo esfuerzos por detectar lo femenino en el varón, en la mujer, en María y ahora se trata de atisbar lo femenino en Dios. De nuevo afirmamos que lo que podemos saber de lo femenino es casi nada en comparación con lo que se nos oculta.

El misterio de lo femenino es eso, misterio, y no problema (que se soluciona); sino que al introducirnos en él cada vez es más misterio, y mayor el desafío para la comprensión. "Lo femenino tiene la estructura de una raiz y de una fuente, vinculado a la Raíz última y a la Fuente suprema"24.

\section{La dimensión femenina como categoría antropológica ${ }^{25}$.}

La dimensión femenina como categoría antropológica puede ayudarnos a detectar y luego sistematizar algunos hechos y afirmaciones acerca de Dios (Padre, Unitrino) y otros que el pensar teológico pueda detectar.

Al profundizar en el designio de Dios sobre la humanidad desde la dimensión femenina se ofrecen distintas posibilidades:

A. BENTUÉ, Las tentaciones de Job, PPC, Madrid 1998, 5-6. El acceso a la realidad de Dios no es fácil, no se trata de buscar seguridades que nos ahorren las dudas sino entrar en la madurez "que ha pasado hasta el fondo por la noche del vértigo", p. 8.

L. BOFF, El rostro materno de Dios. Ensayo interdisciplinar sobre lo femenino y sus formas religiosas, Ediciones Paulinas, Madrid 1979, 11.

Tan peligroso seria mostrar SOLAMENTE un Dios tierno como un Dios guerrero.

L. BOFF, 294. Se afirma que (lo femenino) en María ha conseguido visibilidad histórica y ha alcanzado una anticipación escatológica, símbolo de aquello que habrá de ocurrir con todo lo femenino que se realiza, según su propia manera, en cada uno de los seres humanos. 
- Quienes piensan que por respeto al misterio no cabe ni preguntar por el designio de Dios, sino solo constatar los hechos. Frente a esta postura es factible una llamada a atreverse a pensar y profundizar lo que se sabe para descubrir nueva luz y sentido.

ㄴ Una segunda posibilidad es la de quienes afirman que por la realidad de María, que vivió siempre en función de Dios, ella debe estar presente en toda la teología, ser su hilo conductor ${ }^{426}$.

$\square \quad$ Otra posición consiste en detectar rasgos femeninos de la salvación de Dios en el mundo. Cómo Dios en su libre designio decide que lo femenino tenga un papel en la salvación y en la divinización de la humanidad.

Después de ver esas posibilidades podemos seguir planteándonos: ¿lo femenino es categoría histórico-salvífica universal?, ¿lo femenino es forma de autorrevelación del mismo Dios?

Con temor y temblor podemos apostar, con ciertos riesgos, porque lo femenino sea una dimensión para poder detectar y organizar ciertos datos sobre el Dios Trino, Comunidad de Amor; apostar porque lo femenino tiene que tener algún sentido cuando Dios optó por ser hijo de una mujer; apostar por buscar la pretensión de Dios para sí mediante lo femenino.

La respuesta solo puede ser un "balbuceo" sobre el Misterio supremo que se revela con rasgos femeninos.

\section{La dimensión femenina como categoría de análisis ${ }^{27}$.}

La dimensión femenina no se presenta evidentemente sino que hay que buscarla dentro de y junto a otras dimensiones, y además en las diversas lecturas, filosóficas y/o científicas, que se hacen de la realidad.

Cfr L. BOFF, 22-26. Asi al hablar de antropologia teológica podemos afirmar que es femenino "el primer ser nuevo de la creación renovada por Dios, encabezando la historia escatológica inaugurada por Cristo". Al hablar desde la escatologia "Maria configura la anticipación de la realidad definitiva en el reino de Dios, cuando la materia y el espíritu queden finalmente transfigurados". Y en cada tratado teológico se va especificando el aporte de María, este método lo asumió el Vaticano II (LG 8). Hay que tratar de no perder toda la riqueza que el tema de Maria puede revelar, pues "en ella se encuentra a Dios en una densidad solamente superada por Jesucristo", p. 22. Al hablar de mariologia señalar que ésta sigue a la cristología y lo que acontece en Cristo acontece de modo participado y derivado con Marla, habría que añadir el elemento femenino, virginal, esponsorial y maternal. Al hablar de eclesiologia se descubre a Marla como prototipo de la Iglesia. "Maria era con Cristo un solo cuerpo, una sola vida y un solo amor, ...., María fue la esposa del Espiritu Santo", evitando el peligro de identificación Iglesia y Maria. Al hablar desde el Credo, María es el prototipo de la fe de la Iglesia, se repasan los nueve artículos de fe, puede valer como esquema didáctico y como respuesta a preocupaciones ecuménicas. Al hablar desde el Vaticano II ver que se asume una mariología en clave histórico-salvifica, (LG 55-60). El A.T preanuncia el misterio de Maria: la victoria sobre la serpiente Gn 3,15 y la concepción de Emmanuel ls 7,14. El N.T. donde los humildes portan las promesas Mt 1,22-23 y "En la plenitud de los tiempos se realizó la mayor proximidad de Dios en carne humana; pero la encarnación estuvo precedida de la aceptación libre de Marfa", p. 26. 
Por ello tratemos de ver algunos prejuicios de lo femenino, y por ende de lo masculino; después reconoceremos los retos para una adecuada visión del ser humano (femenino y masculino); y por fin trataremos de reciprocidad y la diferenciación en el ser humano.

\section{a) Prejuicios: alcances y límites del saber.}

Todos nos representamos la realidad, también en este tema de lo humano en femenino y en masculino, condicionados en la manera de conocer que tenemos. Nos influye el lugar, el tiempo, lo que ya pensamos, lo material etc.

La realidad que estudiamos es "intangible", por lo cual lo femenino (y lo masculino, todo lo humano) es construcción (fórmula, modelo, paradigma...). Conocemos por aproximación, por experiencia, por profundización. Lo femenino es concreción del ser humano como lo es lo masculino.

Hacer teologia es preguntar a la luz de la fe, descubrir lo femenino a la luz de la revelación de Dios: como revela lo femenino (junto con lo masculino que es el ser humano) a Dios y como Dios se revela en lo femenino.

\section{b) Algunos retos ${ }^{28}$.}

ㄴ Lo femenino y lo masculino no es algo fijado para siempre; se va configurando en las relaciones, por ello debemos abrir esta realidad humana más allá de la mera racionalidad instrumental analítica.

ㄴ Lo masculino y lo femenino no es un accidente; la Biblia parte de esta diversidad como primera determinación interna del ser humano (Cfr Gn 1,27) y como imagen y semejanza del ser divino.

$\square \quad$ La Iglesia debe asumir una mentalidad que la sociedad ya va haciendo suya: lo humano se realiza en femenino y en masculino.

- Asumir que la diferenciación sexual no se reduce a lo genital; que el ser varón y el ser mujer son realizaciones de lo humano de cada persona.

口 Aceptar la polaridad ${ }^{29}$ varón-mujer como reciprocidad "implica que cada uno participa de la totalidad de la realidad humana y de todas sus cualidades en densidades diferentes. Lo femenino y lo masculino no son accidentes de la naturaleza humana, sino determinaciones esenciales propias de cada ser" ${ }^{\prime \prime}$.

․ Evitar dos escollos, hablar del ser humano sin hablar de varón y mujer y el otro es hablar de ellos sin hablar del ser humano; se trata de hablar del ser humano sexuado y del sexo hominizado (el sexo como algo que es el ser humano, como realidad esencial que coloca a uno frente a otro). 
Con todo esto tratamos de comprender el sentido último de la dimensión femenina en Dios.

\section{c) Diferenciación y reciprocidad.}

Partimos de afirmar la diferencia entre las dos concreciones de lo humano y a la vez recalcamos la reciprocidad.

Primero la diferencia es patente, hay un DIMORFISMO básico. Se da un sexo genético diferente (cada núcleo celular tiene 22 pares cromosomas somáticos y dos sexuales, en la mujer XX y en el varón $X Y$; cada célula esta diferenciada). Además existe el sexo genital (ovario y testículo; cada sexo tienen el esbozo embrionario del otro, hay ŭna bipotencialidad embrional que se orienta hacia uno de los sexos). Existe también el sexo hormonal (glándulas, dirigidas por la hipófisis y el hipotálamo, que segregan hormonas masculinas -andrógenosy femeninas -estrógenos- en proporciones diferentes). Además de lo biológico está lo cultural y ambas realidades interactuan.

A la par, la reciprocidad significa que lo femenino es tal ante lo masculino y también lo masculino es tal ante lo femenino. En esa reciprocidad cada cual se descubre a sí gracias al otro y se experimenta como diferente en todos los niveles de la existencia humana. La relación es de responsabilidad ya que hablamos de reciprocidad más que de complementariedad ${ }^{31}$. La reciprocidad nos lleva a la mutua apertura de uno al otro, la reciprocidad es encuentro de dos alteridades en un ámbito social.

\section{La dimensión femenina como meditación teológica ${ }^{32}$.}

Hemos contemplado que la dimensión femenina es realidad humana y sirve para analizar al ser humano. Ahora ahondemos en lo teológico, en la reflexión a partir de Dios, o sea ver como lo femenino revela a Dios y como Dios se revela en lo femenino.

Esto lo vamos a ver desde la Escritura y la tradición (a) que contienen la revelación de Dios que es histórica y una lectura teológica (b y c).

\section{a) Escritura y Tradición.}

Veamos la dimensión de lo femenino que hay en estas fuentes de la fe. Adelantar que los datos no son demasiado precisos, más bien ambiguos.

Como indicamos al comienzo, pocas veces el A.T. aplica el término padre a Dios. Moltmann afirma que: "En realidad, no se intenta asignar a Dios una sexualidad determinada ni presentarlo como varón ... No obstante en los dos sexos brilla la 
imagen de Dios (Gn 1,27), y la misericordia de Dios se expresa también mediante la imagen de la madre (Is 66,13). En cuanto señor, Dios actúa 'paternal' y 'maternalmente'"'33.

Armendáriz afirma: "Señorío omnímodo de Creador transcendente, libertad y predilección que le adoptan como hijo, y entrañable enternecimiento maternal son los rasgos que configuran la imagen del Padre que Israel aplicó a su Dios"34.

En el A.T. se muestra especialmente la alianza entre Dios y su pueblo y ésta, también, bajo la imagen de las relaciones matrimoniales entre varón y mujer. Aplicado a nuestro tema y en perspectiva de futuro la unión femenino y masculino no se puede quebrantar porque como afirma Balthasar: "Estas relaciones son tan estrechas e indisolubles que no permiten la menor infidelidad, porque el amor de Dios es, por su carácter absoluto, 'celoso' (Dt 4,24; 5,9; 6,15; 32,16.21s; Ex 20,6; 34,14). El amor y los celos aparecen mencionados en conjunción definitiva: "El amor es más fuerte que la muerte, los celos son inexorables como los infiernos" (Cant 8,6)"35.

Lo femenino tenia una presencia significativa en la realidad cotidiana y se exaltaba la dignidad de la mujer en función de la dimensión religiosa ${ }^{36}$.

En el Nuevo Testamento la situación cambia, ya que “... el Verbo de Dios entra como varón, que, ..., se debe a la mujer, ..." ${ }^{37}$.

J. MOLTMANN, 383. Para este autor hay un doble uso del título "padre" a Dios: uno en sentido metafórico (benevolencia y solicitud de su señorio sobre la creación), sería padre del universo; indica "señorio" amoroso, y otro en sentido propio para indicar la relación con Jesús (Hijo unigénito y primogénito), seria padre nuestro (fraternidad y filiación); indica relación de origen del amor.

L.M. ARMENDÁRIZ, "EI Padre Materno" 258. Sigue comentando: "La liberación de Egipto, hito en la historia de Israel, es interpretado por éste al mismo tiempo como un gesto de fidelidad paterna (Gen 17,8; Dt 4,37; 7,8; Ez 16) de Yahweh consigo mismo y con el que era ya su pueblo, y como un arrebato de compasión por él (Ex 3,7$)$ que podriamos calificar de materno".

H.U. VON BALTHASAR, "La dignidad de la mujer", 353. "Puntos centrales de la fe", Biblioteca de Autores Cristianos, Editorial Católica S.A., Madrid 1985, 353-360.

Cfr L. BOFF, 80. "El Judaísmo antiguo, aunque centrado en el varón, permitía una presencia significativa de la mujer en la vida del pueblo. Los textos hablan de la importancia política de Miriam, Ester, Judit, Débora, ...; realzan el papel de las antiguas profetisas y de las antiheroinas Dalila y Jezabel; /.../ el encuentro y el diálogo del siervo de Abraham con Rebeca (Gen 24, 15-67); impresionan profundamente las figuras de Ana, de Rut, de Sara (esta mujer cumple un papel fundamental, es a través de ella como se da cumplimiento a la promesa y no sólo en Abraham, pues éste tuvo otros hijos, recordar que la mujer judia será la que dé a luz al Mesias); y hasta todo el idilio que rodea el amor entre el varón y la mujer en el Cantar de los Cantares". Respecto a esto último BALTHASAR afirma en la página 355 que el Cantar "narra el idilio del esposo real con Sulamitis, la sierva de un pastor. ........los rasgos eróticos de la esposa significará, .... que para Dios son objeto de gozo siempre nuevo, de sorpresa y admiración cada vez mayores, los caracteres con que él mismo engalanó a su pueblo escogido y, tras el pueblo escogido, los caracteres con que el Creador adornó a la criatura en general". A su vez se puede pensar en lo femenino y lo masculino como esos caracteres que alegran a Dios.

H.U. VON BALTHASAR, o.c. 356-357. Dice así: "el Verbo de Dios entra como varón, que, ..., se debe a la mujer, en cuanto a lo humano se refiere (Gál 4,4;1 Cor 11,12). / .../ La Palabra viene a la tierra ya fecundada, es decir, a la fe en ella germinada. ... La fecundidad de Maria ... se sabe respuesta e instrumento (sierva) de la fecundidad de Dios ... . Termina afirmando que "La feminidad de toda criatura (sea macho o hembra) es constitutiva de su esencia". 
La pater-maternidad de Dios está fuertemente marcada en las palabras de Jesús, cuando compara a Dios con un padre que no sabe negar a su hijo lo que le pide, que aguarda que vuelva a casa (Cfr Lc 11,13.15). Jesús habla de "vuestro Padre" refiriéndose a los suyos, de quienes conoce sus necesidades, les perdona, les cuida (Cfr Mt 6, 8-32; Mc 11, 25; Lc 12,30). No se puede expresar mejor el amor de una madre, son los rasgos femeninos de su paternidad. Jesús también habla de "mi Padre $^{n}$ en un sentido unívoco y absoluto (Cfr Mt 11, 27; 11,25; 16,17; Mc 4, 11; 13,22; Lc 10,$23 ; 22,29$; etc.). La expresión definitiva es "abbá", Jesús la emplea siempre en su oración y tiene un rasgo de compasión y ternura que muestra el lado femenino de Dios $^{38}$.

Jesús instaura "la ética de la responsabilidad y del amor que se expresa en el reconocimiento de la persona y en la búsqueda de relaciones fraternales entre los hombres"39.

Las actitudes y el mensaje de Jesús significaron una ruptura con la situación imperante y una inmensa novedad dentro del marco de aquella época ${ }^{40}$.

Después de Jesús las mujeres desempeñaron en la comunidad cristiana ciertas actividades destacadas en el anuncio y en la práctica de la $\mathrm{fe}^{41}$.

L. BOFF, 83. Veamos ese modo nuevo de ser de Jesús: Es seguido por mujeres (Lc 8,1-3. Maria, Juana, Susana y otras); es amigo de Marta y Maria (Lc 10,38-42); habla con la samaritana ( $\mathrm{Jn} 4,1-42)$; defiende a la adúltera ( $\operatorname{Jn} 8,1-11)$; enaltece a la viuda pobre que echó dos moneditas (Lc 21,1-4); se deja tocar por la mujer de Magdala (Lc 7,36-50); se deja ungir en Betania (Mt 26,613; Mc 14, 3-9), esta pericopa termina con la frase de Jesús: "... en el mundo entero se hablará de lo que ésta ha hecho para memoria suya", el evangello de Juan también tiene la unción en Betania (Jn 12,1-8) pero no tiene ese final; envia a $\mathrm{M}^{\mathrm{a}}$ Magdalena a anunciar la resurrección ( $\mathrm{Jn} 20,11-18$ ); atiende a la suegra de Pedro (Lc 4,38-39), a la madre del joven de Naím, (Lc 7,11-17), a la niña muerta de Jairo (Mt 9,18-19. 23-26), a la mujer encorvada (LC 13,10-17), a la pagana sirofenicia (Mc 7, 24-30) y a la mujer que llevaba 12 años enferma con flujo de sangre (Mt 9,20-22).

Cfr B. VILLEGAS, "Obispos y Presbiteros", Anales de la Facultad de Teología, Pontificia Universidad Católica de Chile 37 (1972) 90. Se incluyen mujeres dentro del ministerio diaconal (1Tm 3,$11 ; \mathrm{Rm} 16.1$ ), tamblén se habla de las "viudas" de una manera tal que es inevitable pensar que se trata de un grupo ministerial (1Tm 5,3-16). Cfr E. SCHÜSSLER FIORENZA, "Presencia de la mujer en el primitivo movimiento cristiano": Concilium, 111 (1976), 9-24. I...I. Las mujeres trabajaron duro por el Señor $(\mathrm{Rm} 16,12)$; conocemos a Priscila, a Febe diaconisa de la iglesia de Cencreas (Rm 16,1), a Maria, Pérside, Julia, Trifena y Trifosa, la hermana de Nereo y Rufo. Los Hechos de los Apóstoles nos hablan de Lidia (Hch 16,14-15), negociante de púrpura, rica y activa en la comunidad; de Dámaris $(17,34)$; de algunas profetisas como las cuatro hijas vírgenes de Felipe $(21,9)$; de otras que confeccionaban ropas para los pobres $(9,36 \mathrm{ss})$. Pablo habla además de Evodia de Sintique, que le asistian en su lucha por el evangelio (Flp 4,2). 
Pablo tuvo mucha importancia y en sus textos aparece la tensión entre lo cultural y la novedad aportada por Jesús ${ }^{42}$.

En la tradición cristiana se sigue manteniendo el conflicto, en la teoría tiene que haber igualdad pero en la práctica continúa la subordinación (de la mujer al varón). Es lo mismo que ocurrió también con la esclavitud: se percibe una incapacidad histórica para pasar de la teoría a la práctica. Aun así, se puede constatar que siempre hubo por alguna que otra parte representaciones de lo femenino que se pueden recordar ${ }^{43}$.

\section{b) Antropología teológica.}

En esta lectura teológica señalemos brevemente algunos apuntes para una Antropologia Teológica que integre lo femenino.

La humanidad es imagen de Dios.

El primer principio que afirma la Biblia es que: "Dios creó al ser humano a su imagen..., varón y mujer los creó“ (Gn 1,27). La imagen es completa cuando se refleja en los dos modos de ser lo humano. Esto se dice también en Gn 5,1-12: "Cuando el Señor creó al hombre, lo hizo a su propia imagen, varón y mujer los creó, los bendijo y los llamó Hombre al crearlos"44. señala que "la mujer debe llevar en la cabeza una señal de sujeción" y en los vv11-12 "el hombre nace por la mujer", con lo cual aparece "la ambigüedad entre el elemento cultural y el que procede de Jesús". El segundo texto es Ef 5,21-33, en donde Pablo habla de la relación entre el hombre y la mujer dentro del matrimonio. Inicialmente se afirman unas relaciones disimétricas $(5,22-24), / \ldots$ I toma este matrimonio y lo convierte en tipo de la relación que hay entre Cristo y la Iglesia, ... no se quiere definir las relaciones entre marido y mujer. /.../ Después ... como si recuperase la novedad cristiana: "Debe amar a su mujer como asi mismo, ya que los dos son una sola carne" (5, 25-33). A pesar de las ambigüedades, se procura restablecer el equilibrio". También se puede consultar K.E. BORRESEN, "Fundamentos antropológicos de la relación entre el hombre y la mujer en la teología clásica", en Concilium 111 (1976), 25-40.

Cfr L. BOFF, 92. El autor cita a: Blandina, Agueda, Lucia, Inés, las mártires, la abadesa Hilda de Inglaterra (680), que presidió el sínodo de Whitby donde se decidió aceptar la fecha romana de la pascua con todas las consecuencias ligadas a este hecho; a santa Catalina de Siena consejera de los Papas Gregorio XI y Urbano VI en el siglo XIV; a santa Teresa de Avila, la gran mística teóloga y reformadora del catolicismo español del siglo XVI; a santa Juana de Arco, la guerrera y mártir de la verdad con un coraje demasiado "varonil" para los cánones de aquel tiempo; a Juana Angélica del Brasil ... y a otras muchas mujeres .../.../ Concluir afirmando la "profunda ambigüedad de las fuentes de la fe, la Escritura y la tradición".

Cfr L.M. ARMENDÁRIZ "El Padre Materno" 260. En la nota 30 afirma que así lo entiende C. WESTERMANN para quien este relato es excepcionalmente favorable a la dignidad de la mujer. Continúa: "Pero es muy posible que estos impulsos renovadores de la revelación no lograsen imponerse a la corriente sociológica que privilegiaba al varón y vetaba la atribución del título materno a Dios". De hecho la historia no siempre lo ha entendido de aquella manera, se puede consultar el artículo de BINGEMER, en las páginas 137-141 donde se señala el triple dualismo (cuerpo-alma, cielo-tierra y eficiencia-gratuidad o pragmatismo-experiencia o acción contemplación) que da origen a ciertos malentendidos. 
Reciprocidad desde la diferenciación.

"iEsta si que es huesos de mis huesos y carne de mi carne! ${ }^{45} / . . . /$ Por eso ... se abandona padre y madre, ... y se hacen una sola carne" $(G n 2,24)$. Varón y mujer con la misma naturaleza y dignidad, ambas concreciones de lo humano.

"Mi amado es mío y yo soy suya" (Cant 2,16 y 6,3 ). Varón y mujer en reciprocidad formulada en el Cantar de los Cantares ${ }^{46}$.

"Ni hay mujer sin varón, ni varón sin la mujer" (1 Cor 11,11); también "la mujer ya no es dueña de su cuerpo, lo es el hombre, y tampoco él es dueño de su cuerpo, lo es la mujer" (1 Cor 7,4); "Sed dóciles unos a otros por respeto a Cristo" (Ef 5,21). Afirmaciones de Pablo refiriéndose a la reciprocidad entre los esposos.

(iii) Dios también se revela bajo lenguaje femenino.

Solamente recoger algunas citas ya dichas y conocidas: La Personificación en la Sabiduría (Prov 8,22-26; Eclo 24,9; 1 Cor 24,30); y la correlación entre lo femenino y la Sabiduría (Prov 31,10.26.30; 19,14; 40,12; Sab 3,12; 7,28).

Los profetas presentan a Dios como a quien se le conmueven las entrañas (Jr 31,20 ); como la parturienta que a punto de dar a luz grita (Is 42,14 ); como la madre que consuela (Is 66,13); que no olvida del hijo de sus entrañas (Is 49,15; Sal25,6; 116,5); y que enjugará todo llanto (Ap 21,4).

Jesús rescata y apuesta por lo femenino que reúne bajo su protección (Lc 13,34).

Pablo en "su 'paternidad espiritual' usa imágenes de la maternidad: 'Sufro dolores de 'parto hasta que se forme Cristo en ustedes' (Gal 4,19) ${ }^{n 47}$.

Por fin, la iniciativa, la continuidad y la plenitud son femeninas. Al comienzo es María quien acepta la propuesta de Dios. La fidelidad al lado de la cruz tiene rostro femenino (los otros han huido Mt 27,56). El anuncio de la resurrección tiene unas primeras testigos (Mt 28,19-20). En el evangelio de Juan lo femenino tiene un fuerte papel en la iniciativa de la fe: María en las bodas de Caná $(2,11)$; la samaritana lleva la fe a sus conciudadanos (4,1ss); Marta y María en la resurrección de Lázaro (11,21$30) ; M^{\mathrm{a}}$ Magdalena anuncia la resurrección (20,1-18).

Cfr P. EVDOKIMOV, La mujer y la salvación del mundo, Sigueme, Salamanca 1980, 145-146. Comenta este autor: "¿No son más bien las palabras que toda madre hubjera dirigido a un hijo suyo? Su inspiración poética acentủa todavia más el hecho de ... un auténtico alumbramiento: Eva se desprende de Adán. /...l. El nacimiento de Eva se nos presenta, pues, como el gran mito de la consubtancialidad de los principios complementarios de todo ser humano".

Cfr Ib., 149. De este texto EVDOKIMOV afirma: "... dos seres frente a frente se repiten aquellas palabras del Cantar de los Cantares. Su existencia es reciprocidad transparente, pertenencia a Dios. Ser el uno para el otro y el otro para el uno, es el modo humano de pertenecer a Dios./.../A ambos en reciprocidad es a quien se dirige Dios,... nunca se dirige al hombre solo 0 a la mujer sola: jamás los separa".

lb., 159. "... lo más asombroso que aún nos queda por descubrir es el hecho de que el hombre no posee el instinto paternal en el mismo grado e intensidad que la mujer posee el instinto maternal. /.../ Significa que, en lo humano, el principio religioso se expresa por la mujer, que la particular sensibilidad a lo espiritual puro se halla en el anima y no en el animus, y que es al alma femenina la que está más cerca de las fuentes originales del Génesis". 
Para terminar con estas escuetas pinceladas para una antropología teológica que integre lo femenino, se puede afirmar que la plenitud del ser humano, de la mujer y del varón, está en Dios ${ }^{48}$.

\section{c) Doble camino: Dios en lo femenino y lo femenino en Dios.}

(i) Una dimensión del ser humano hacia Dios y de Dios hacia el ser humano.

Podemos afirmar que lo femenino es un camino para Dios, ya que es imagen de Dios. El ser humano, en cuanto varón y mujer, es imagen radical de la Trinidad ("Hagamos al ser humano a nuestra imagen" $\mathrm{Gn} 1,26$ ), donde lo fundamental es la relacionalidad recíproca ${ }^{49}$.

Dios unitrino se puede considerar prototípicamente masculino y femenino, asi lo femenino del ser humano nos revela lo Femenino de Dios. Y al afirmar la dimensión femenina en Dios decimos que también las cualidades femeninas y maternales, como las paternales y filiales, se realizan absolutamente en Dios (y solo parcialmente en varones y mujeres) ${ }^{50}$.

Para iluminar estos movimientos del ser humano hacia Dios y de Dios hacia el ser humano debemos considerar la acción salvadora entre nosotros ${ }^{51}$.

Algunos testimonios históricos presentan elementos femeninos de Dios ${ }^{52}$.

Finalmente recordar la frase del Papa Juan Pablo I en una audiencia pública:

Cfr L. BOFF, 98. "El destino último del varón y de la mujer es Dios mismo. En el desposorio eterno con él es como se realiza la plenitud del ser humano en su diferenciación masculina y femenina".

Cfr L. BOFF, 99-100. "Al contemplar lo que significa lo femenino (en el varón y en la mujer) con sus dimensiones de vida, de profundidad, de misterio, de ternura, y de cariño, la fe se encuentra con Dios. ... Lo femenino es una obra suprema de Dios, ya que solamente de él y de lo masculino se dice que son imagen y semejanza de Dios.... juntos forman una unidad dual (expresión utilizada por BALTHASAR en su Teodramática II, 340) que a su vez no se sacia a si misma. ... . La mujer y el varón sólo se personalizan radicalmente si se sumergen juntos en el Misterio".

$50 \quad$ Pero a la vez decimos que Dios supera toda determinación, también la sexual, y que nuestro hablar de Dios es analógico, afirma una semejanza y una mayor desemejanza.

Cfr M.C. BINGEMER, 152-162. Se analiza cada una de las personas divinas para percibir los rasgos que emanan de ellas en cuanto a su revelación en lo femenino. Así a) el Hijo: fundador de una comunidad de hombres y mujeres, b) El Espiritu: Amor maternal increado; c) El Padre Maternal y la Madre Paternal.

Cfr J. ARNOLD, "Maria, la maternidad divina y la mujer. Estudio de unas imágenes cambiantes": Concilium, 111 (1976), 54-67. En la cultura hebrea el Espiritu de Yahvé es femenino. El término rûah se traduce en los Setenta, al griego, por pneuma, de género neutro, y al latín por spiritus que es masculino. "Todavía a comienzos de la Era cristiana es posible encontrar los rastros de una idea maternal del Espíritu. Asi, un fragmento del perdido 'Evangelio de los hebreos' presenta a Jesús diciendo: Ahora mismo mi madre el Espiritu Santo me tomó por uno de mis cabellos y me llevó al gran monte Tabor, p. 57. También la mística Juliana de Norwith (citada ya por RUETHER 398 que presenta a Jesús como padre y madre a la vez en la espiritualidad eucaristica: imagen maternal, nutricia ya que nos alimenta con su cuerpo; y por BINGEMER 150): "describe a Jesús como una madre que la alimenta con la leche de su pecho, que es su costado herido. La descripción que hace esta mujer rebosa devoción, admirada de que Jesús entregue su cuerpo a su amante humano. La madre humana -exclama en éxtasis Juliana- amamantará a su hijo con su propia leche, pero nuestra Madre amada, Jesús, nos alimenta con su propio cuerpo....", p. 61. 
"Dios es Padre, pero sobre todo, es Madre"53. Así mismo Juan Pablo Il en su encíclica "Dives in misericordia" señala el aspecto femenino de la misericordia de Dios.

(ii) Dios principio último de todo lo humano, también de la femineidad. Hemos visto que tanto lo femenino como lo masculino son realidad que comunican a Dios, ambos son imagen de Dios (Gn1,27).

La comprensión moderna de que cada uno de los seres humanos es animus y anima, simultáneamente pero en proporciones diferentes ${ }^{54}$.

Mirando a la Trinidad descubrimos que:

Dios trino, a semejanza-desemejanza del hombre y viceversa, se realiza en una unidad y en una diferencia. Puede ser experimentado como femenino (profundidad misteriosa e insondable; origen sin origen, ) y como masculino (autocomunicación en verdad y amor; donación y extroyección) ${ }^{55}$.

Que El Padre es activo al producir al Hijo entregándose, el Hijo es pasivo y activamente se entrega agradecido y el Padre es pasivo al recibir la agradecida entrega del Hijo y activo al donarse, el Espíritu Santo es pasivo no produce otra persona y es activo creando el nosotros, se da la conjunción de masculino y femenino. Finalmente, los sexos "se deben conjuntamente al Padre eterno /.../ De él proceden a la postre ambos sexos con igual Padre, más aún, es Madre. No quiere nuestro mal; sólo quiere hacernos bien a todos. Y los hijos, si están enfermos, tienen más motivo para que la madre los ame". JUAN PABLO I, Enseñanzas al Pueblo de Dios, Librería Editrice Vaticana, Cittá del Vaticano 1978, 5.".

Cfr L. BOFF, 110. Se afirma: "La comprensión moderna de que cada uno de los seres humanos es animus y anima, simultáneamente pero en proporciones diferentes, masculino y femenino ... Jesús es masculino y femenino: vivió plenamente lo masculino (ya que era varón), pero integrando perfectamente la dimensión femenina. Pues bien todo en Jesús, también lo femenino, fue asumido hipostáticamente por el Verbo eterno. Al menos en Jesús lo femenino pertenece a Díos y ha sido divinizado; según las reglas cristológicas de la perijoresis, este femenino de Jesús es Dios".

Cfr L. BOFF, 111. Explicando el contenido de la Trinidad dice: "Padre expresa la realidad divina en cuanto que es principlo sin origen de todo, la fuente de la que todo brota y a la que todo vuelve. Hijo es esa misma realidad divina en cuanto que es autocomunicada como Verdad de sí misma, como expresión infinita de sí misma hacia fuera de sí misma. Espíritu Santo es esa misma realidad divina en cuanto que al comunicarse a si misma produce la aceptación amorosa de su comunicación en aquel que la recibe. La santísima Trinidad es, por tanto, momentos de la única autocomunicación de Dios, del Misterio insondable que sale .../.../ descubrimos analógicamente la misma estructura que encontramos también en el ser humano; hay una unidad plural y un pluralismo de modos de ser y de existir del uno". ${ }^{10}$ El texto griego dice ekeinos exegésato: "El lo dio a conocern; la forma verbal exegésato está en aoristo indicativo del verbo exegéomal, que se puede traducir por: «dio a conocer», «reveló",»expuso" o "explicó». De aquí también nacen dos sustantivos: «exégesis» y «exégeta». Entonces, podemos decir, que el Hijo único se ha convertido en exégeta del Padre. 
dignidad, pero no es él, sino el Hijo, el arquetipo de hombres y mujeres" 56 . La doctrina trinitaria del cristianismo y sus afirmaciones sobre el Padre materno representan un "primer paso" para descubrir categorias femeninas en Dios ${ }^{57}$.

Además, al hablar del cristianismo como la religión del Hijo se facilita la tarea de descubrir en Dios lo femenino adjudicándolo desde el dato de que en el Hijo lo femenino y lo masculino está garantizado. Esto ultimo unido a lo de Balthasar da ocasión para recuperar lo femenino en Dios por parte del Hijo que despierta en el Padre actitudes femeninas, dolor, congoja, paciencia, abandono...

H.U. VON BALTHASAR, "La dignidad de la mujer", 359-360. Afirma lo siguiente: "... hay dos formas de entrega amorosa en el seno de la vida unitrina de Dios: una donación puramente activa y otra de recepción y respuesta activo-pasiva. Ambas formas son igualmente eternas y eternamente reciprocas. El Padre, origen sin origen, produce eternamente al Hijo por la entrega total de sí. El Hijo, en cuanto eterno receptor, es "pasivo", pero no es menos deudor agradecido ("eucaristia") que "activamente" se devuelve al Origen, de suerte que la bienandanza eterna del Padre consiste tanto en la "pasiva" recepción de la agradecida entrega del Hijo como en la eterna donación de sí. La procesión del Espíritu Santo del Padre y del Hijo no es pura pasividad, por eso de que no produce otra persona divina. Es más bien una forma de deberse reciprocamente el propio ser, en que el amor pasivo-activo es "nosotros", intercambio esencial, don puro. /.../Mirando al Hijo vemos "el arquetipo de la conjunción de lo primariamente "femenino" con lo "masculino" que le es inseparable, pero ontológicamente subsiguiente"./.../ "en las procesiones trinitarias eternas no hay momento en que el Hijo reciba su mismidad del Padre sin debérsela y devolvérsela en el mismo momento". I .../ Continua afirmando "Los arquetipos de los dos sexos son en el Hijo igualmente eternos e igualmente dignos, en el supuesto de que el Hijo le deja al Padre, origen no originado, el primer puesto en el orden de las procesiones".

Cfr J. MOLTMANN, 385-389. Afirma: "Si el Hijo procede sólo del Padre, tal procesión debe interpretarse a la vez como "procreación" y como "alumbramiento". Ahora bien, con esto cambia radicalmente la imagen del Padre: un padre que no sólo engendra al hijo, sino que también lo alumbra no es un padre exclusivamente masculino. Es un padre materno. /.../. Es a un tiempo Padre materno de su Hijo "uninato" y Padre paterno de su Hijo unigénito. Este es un punto en que la tradición dogmática ortodoxa ha formulado sus más osadas declaraciones. Según el concilio celebrado en Toledo el año 675 "debemos creer que el Hijo no procede de la nada ni de alguna otra substancia, sino que ha sido engendrado o alumbrado (genitus vel natus) del seno materno del Padre (de utero Patris), es decir, de su sustancia" (Cfr H. DENZINGER, Enchiridion Symbolorum, 276: "Nec enim de nihilo, neque de aliqua alia substantia, sed de Patris utero, id est, de substantia eius idem Filius genitus vel natus esse credendus est"). L.M. ARMENDÁRIZ, "EI Padre Materno" 269 , respecto a esto se pregunta "¿Cabe una expresión más audaz, y al mismo tiempo más legitima y densa, de la maternidad del Dios Padre?".

Continúa MOLTMANNN con los nuevos ensayos sobre Trinidad, cita a BALTHASAR MS III, Cristiandad, Madrid 1969, 143-335. Los articulos "Cruz y Trinidad" 233-237 y "El resucitado atestigua acerca de si mismo" 291-297 dan pie para hablar del "sufrimiento de Dios". Asi Heschel elabora un concepto bipolar de Dios. También afirma MOLTMANN: "La concepción judia de la teopatía presupone esta "autodiferenciación en Dios. En tal perspectiva, la omnipotencia de Dios debe contemplarse con toda su capacidad de sufrir", p. 387. Continúa afirmando que si Dios es amor, el amor implica capacidad de sufrir. Cita a UNAMUNO que habla de la congoja de Dios, del Cristo de Velázquez que muestra el dolor infinito del Padre, el Dios doliente (386-387). Añade: "Nuestra liberación del dolor y nuestra redención del sufrimiento surgen del sufrimiento de toda la Trinidad: de la agonia del Hijo, de la congoja del Padre y de la paciencia del Espíritu. Dios libera para la vida por medio del amor doliente. Lo que es divino es ese amor, no el poder..., p. 388.

Finalmente: "Cuando creemos en Dios como padre, experimentamos la libertad en la filiación divina; quien se considera hija/o de Dios, es miembro de la familia con paridad de derechos. No sólo escucha a un señor, sino que también es escuchado por el padre. Por eso no es el cristianismo una religión del padre, sino la religión del Hijo". 


\section{LA gracia como ROStro fEMENINO DE DIOS ${ }^{58}$.}

\section{La dimensión femenina de Dios.}

Se puede descubrir a través de algunos rasgos presentes en la vida cotidiana llevados a su máxima profundidad.

La belleza como reflejo, espejo, prisma que sobrepasa la estética, como proyección de fuerzas reunidas. La belleza del crucificado, de los sin rostro. La belleza del esplendor de la creación, las flores, los niños, el banquete de bodas y tantas otras realidades que guardan escondida la belleza de Dios $^{59}$. Estamos en el ámbito en que Dios Origen (el Padre) se autocomunica y nos llega su esplendor.

La transparencia mediante la cual se traspasa el envoltorio, queda superado lo perceptible por los sentidos; abre infinitos horizontes. La imagen y semejanza de Dios en la Biblia se transparenta en dos seres humanos, Adán y Eva. Dios tiene que tener rasgos femeninos y masculinos. Estamos en el ámbito en que Dios con nosotros (el Hijo) se nos muestra y nos llega su bondad.

La alegría nos da un rostro abierto, espontáneo, libre, gozoso, doloroso; un rostro que mana, que nos habla de una existencia que fluye que se derrama. El Espíritu de Dios, la rûah que vivifica, confiere verdad y valor. Creer en el Espíritu de Dios significa invocarle jVEN ESPIRITU SANTO!. Es un fondo, una totalidad que nos unifica. Estamos en el ámbito en que Dios-Amor (el Espíritu Santo) se nos dice y nos llega su verdad.

La donación, es una salida de sí, un ser enviado. Un rostro que muestra ser don para otros, ser portador/a y porteador/a. Es creer en la fuerza creadora que "llama a la existencia a lo que no existe" $(\mathrm{Rm} 4,17)$. Ser dador de vida va estrechamente unido a ser salvación para otros ${ }^{60}$. Una clara ima-

Cfr C. KAUFMANN, El rostro femenino de Dios. Reflexiones de una carmelita descalza, DDB, Bilbao 1998, 38-45.

Cfr A. MELÉNDEZ, "Las 'Edades del hombre': el Rastro de Dios en una historia concreta": Sal Terrae 1020 (1999) 148. "Hans Urs von Balthasar decia: "Nuestra palabra inicial se llama belleza. La belleza en la que no nos atrevemos a seguir creyendo y a la que hemos convertido en una apariencia para poder librarnos de ella sin remordimientos. La belleza que, como hoy aparece bien claro, reclama para si tanto valor y fuerza de decisión como la verdad y el bien, y que no se deja separar ni alejar de sus dos hermanas sin arrastrarlas consigo en una misteriosa venganza. De aquel cuyo semblante se crispa ante la sola mención de su nombre, pues para él la belleza sólo es una chucheria burguesa, podemos asegurar que -abierta o tácitamente-ya no es capaz de rezar, y pronto ni siquiera será capaz de amar". Y es que la belleza de verdad es el recordatorio visible de la Luz invisible; la belleza a través de la cual se ha de comunicar el Misterio, lo Inefable". En la misma revista se pueden consultar los artículos de D'ORS, BARBERÁ y DÁZ DE LA ESPINA que tratan el tema de la belleza bajo el título de "Abrir caminos a la belleza de la fe". También M.T. PORCILE, "El derecho a la belleza en América Latina", en El rostro femenino de la teologia, WAA, Editorial Departamento Ecuménico de Investigaciones (DEI), San José-Costa Rica(1986) 85-107.

Cfr ELDA RAMÍREZ, "La mujer creada a imagen y semejanza de Dios", Revista ITER, Caracas, 1 (1999) 61-80. Esta autora afirma que dador de vida y salvación, dar la vida es recrearla, salvarla, son dos rasgos unidos que Dios muestra de sí en lo femenino. Unida a la donación va la fidelidad en todo tiempo (Is 49,15 no te olvidaré jamás), p. 72. 
gen la tenemos en María como "donación total de si" ${ }^{61}$. Estamos en el ámbito en que la Primera Persona (el Padre) se autocomunica y nos llega su esplendor.

La sanación que provoca la acogida incondicional que es producto de la dulzura, de la ternura, del exceso o desmesura de amor (Lc 15). Sanación aunque quedes coja/o como Jacob (Gn 32, 23-32 lucha con Dios) ${ }^{62}$. Desde el cristianismo no hay respuesta (argumentación razonable) para el mal. "En Jesús, Dios ASUME en carne propia el escándalo del mal, en su forma más aberrante: Jesús, el inocente absurdamente atropellado"63. Estamos en el ámbito en que la segunda Persona (el Hijo) se nos muestra y nos llega su bondad.

La vulnerabilidad experimentada en la profundidad del amor, en la intemperie de la soledad, en lo inerme de los sentimientos misteriosos e inexplicables. A mayor crecimiento en el amor mayor vulnerabilidad. En la soledad la cruz se hace árbol de la vida, la promesa no es un jardín de rosas sino la cruz que reverdecerá. En María de Nazaret Dios se entrega al ministerio libre y activo de una mujer ${ }^{64}$. En todo ser humano el sentido de la vida y de la muerte está en la misericordia ${ }^{65}$. La vulnerabilidad surge de la

Cfr A. MEIS, "Maria, la Mujer", Teologia y Vida 29 (1988) 147-170. En este artículo MEIS afirma: "El Santo Padre presenta a María como "donación total de si". La celebra así, con la liturgia oriental, como el principal regalo que ofrece la humanidad al Hijo de Dios que se encarna (Cfr Redemptoris Mater 39, 4431 y 32). /.../. Si el Logos, pues procede eternamente del Padre, ¿no podrá concebir su actitud para con el Padre como femenino?. I.../. Pero lo femenino debe proceder del varón Cristo, de su plenitud, del mismo modo como Eva fue formada a partir de Adán, quien la lleva consigo potencialmente", p. 150.

Cfr D. SÖLLE, Cap, 4. Algunos ven que es la historia de la propia vida, todos hemos luchado con Dios. Situaciones de tránsito en la vida, en la que hemos de pasar un vado, por ejemplo el asalto de lo trivial, el espiritu de lo cotidiano que materializaba brutalmente nuestras actividades y nuestros Sueños y también la angustia ante el envejecer, la soledad, la decrepitud que poco a poco se desliza en cada uno. Este pasaje también se ha pintado y Rembrandt en su cuadro "Jacob lucha con el ángel", muestra una lucha que es abrazo, las dos figuras se funden en una sola como en relación erótica. La lucha de fuerza se convierte en lucha de oración. La oración es el lugar en que Dios es vencido y se deja vencer. La oración y la lucha se hallan unidas, luchamos para que no se muera la persona amada. Oramos más cuando amamos más, le agarramos a Dios para que no nos suelte, peleamos para Dios sea Dios y la vida triunfe. En la oración nos enfrentamos con quien cae sobre nosotros.

A. BENTUÉ, Cuitura de hombres, salvación de Dios, Tiberiades, Santiago de Chile, 1999, 154. Se puede consultar todo el apartado sobre Jesús y el mal desde 153-158. En Rm 8, 22-23 Pablo afirma que la creación y nosotros gemimos con dolores de parto "anhelando la adopción filial". El autor dice: "El mal se combate reconociéndome ante todo como un hermano y no como enemigo de quien hizo o me hizo daño", p. 158.

Cfr A. MEIS, 153. EI Papa en R.M.46, afirma: "La figura de Maria de Nazaret proyecta luz sobre la mujer en cuanto tal por el mismo hecho de que Dios, en el sublime acontecimiento de la encarnación del Hijo, se ha entregado al ministerio libre y activo de una mujer".

Cfr A. BENTUÉ, 167. "El 'fin del mundo' se da en el ahora y aqui de la vida y de la muerte experimentada como lugar de la misericordia de Dios para con nuestra pobre fragilidad y, motivados por ello, como lugar de nuestra propia decisión misericordiosa para con quienes nos rodean, en situación de fragilidad". 
ternura y predispone al perdón ${ }^{66}$. Estamos en el ámbito en que la tercera Persona (el Espiritu Santo) se nos dice y nos llega su verdad.

La receptividad como respuesta activa, es un vaciamiento para recibir. Todo llamamiento, toda vocación es don y tarea. La voz de Dios nos llama y nosotros respondemos. También la receptividad se nos muestra en María, quien dándose, vaciándose se transforma en llena de gracia ${ }^{67}$. Somos más activos cuando nos abandonamos a la receptividad. La salvación llega a nosotros cuando nos situamos en "apertura receptiva" ${ }^{68}$. Estamos en el ámbito en que la Tercera Persona (el Espíritu Santo) se nos dice y nos llega su verdad.

\section{El rostro de la gracia.}

El rostro de la gracia es misterio: es ocultamiento-desvelamiento; el misterio de origen, de la fuente. El rostro de la gracia revela el misterio sin desvelarlo; lo muestra pero no lo demuestra. Lo transparenta, no lo enfrenta sino que lo traspasa. Lo manifiesta, no lo impone.

El rostro de la gracia hace que:

María sea una gran revelación de lo femenino de Dios. Es la engendradora del Dios encarnado, en quien Dios cumple su promesa de salvación. Ella es mediadora de la salvación de Dios. Dios se muestra como el dador de la vida y elige "la mediación más perfecta que El formó para recrear y multiplicar la vida"69.

María acepta, con su sí definitivo, el proyecto de nueva creación y nueva humanidad. El Dios que proyectó cómo serían la creación y la historia, proyectó en María cómo sería la humanidad ${ }^{70}$.

Jesús sea la imagen perfecta de Dios (quien me ha visto a mí, ha visto al Padre (Cfr Jn 14,9) que integra "las diferencias de lo masculino y lo femenino. En Jesús Dios se nos revela como un Dios que integra en su ser la dimensión femenina de lo

Cfr E. RAMIREZ, 71 y 78 . Esta autora afirma que "vulnerabilidad y debilidad ante el poder humano ... y a la vez fuerza transformadora y vivificadora en el amor".

Cfr A. MEIS, 153. "María... se da con toda su persona humana femenina en respuesta el "donum ipsius Dei", de tal manera que ella, siendo regalo, don de sí, se ha transformado en "llena de gracia" (RM10). La gracia, pues, determina la extraordinaria grandeza y belleza de todo su ser, hasta tal punto que el nombre propio nuevo de Maria es ahora "llena de gracia", por ser ella "espejo de las maravillas del Señor" en la RM 89".

A. BENTUÉ, 152. "La actitud creyente propia del cristianismo es la apertura receptiva a una salvación gratuita, que se da en Cristo. Ella y sólo ella permite superar el absurdo autónomo de la existencia con sus coordenadas de inconsistencia, muerte y egocentrismo". De la misma manera se expresa DOLORES ALEXAINDRE, en un folletito sobre la oración, 19. "... la realidad es que nunca somos más activos y dinámicos que cuando emprendemos la aventura de la receptividad, que es el nombre que recibe el amor cuando decide responder a otro Amor mayor que le reclama consentimiento y acogida". 
humano. Dios en su misericordia se nos acerca con un rostro "que es espacio de vida y salvación"71.

Dios está todo en Jesús, toda la substancia de la divinidad corporalmente ${ }^{72}$. (Paradójicamente en un ser humano está la divinidad y en un varón la feminidad).

El rostro de la gracia pide:

Revitalizar la Iglesia en sus dimensiones, potencialidades también femeninas.

․ Expresar y proclamar la misericordia amorosa para con lo débil: ¡Ven Espíritu Santo, dulce huésped del alma!.

Reflejar el consuelo, la amistad, proyectar sosiego, reposo, silencio.

Ser mirado, contemplado en oración.

Enjugar sudor, lágrimas, consolar (sin pretender que el dolor desaparezca). Suavizar, ablandar, y enderezar lo torcido, incluir el dolor como parte de la vida. El humor y la seriedad. Mostrar lo femenino, tratar con delicadeza-firmeza; ternura-vigor ${ }^{73}$.

․ Estimular a todos para adquirir virtudes femeninas como Teresa de Avila pedia a las mujeres virtudes varoniles ${ }^{74}$.

ㅁ Dejarnos habitar por el Espíritu Santo ${ }^{75}$.

3. Redescubriendo lo femenino.

Para condensar lo dicho podemos afirmar:

El Origen (Padre) se da como Misterio de ocultamiento-desvelamiento, se revela sin desvelar. Este Origen se da en la creación, en el esplendor. Este Origen es la generación, es Fuente, Vida, Donación, Belleza.

$\square$ EI Receptor (Hijo) que se autoentrega hace que la realidad muestre la transparencia, la sanación, la adopción. Es camino, pozo de Agua Viva, obediencia. Hace que el fin se nos acerque ya que es "imagen perfecta", es plenitud de lo humano.

$\square \quad$ La Vida (Espíritu Santo) se dice en la alegría (y el dolor), la vulnerabilidad (y la firmeza), en la aspiración. Es receptividad, es mar oceánico, es meta a la que llegaremos en comunión con toda la realidad en la Iglesia, comunidad revitalizada de Amor por su presencia.

E. RAMIREZ, 77.

Cfr C. KAUFMANN, 40; A. SERRANO, 114.

Cfr D. SÖLLE, Cap. 5. Dios nos consuela como hace una madre: no tiene medios de hacer que el dolor desaparezca (jaunque eso algunas veces pasa!), pero nos aprieta cabe sí, en su regazo hasta que volvemos a enderezarnos y nos sentimos con nuevo vigor. Traer un hijo al mundo es experiencia del misterio de la vida, que incluye el dolor, /.../ necesitamos vincular nuestros dolores al dolor de Dios para adoptar la actitud debida ante el sufrimiento. El sufrimiento se padece y se asimila. 
Para ir terminando unos últimos aportes:

Blanca Castilla en el epígrafe 8 titulado "Paternidad, filiación y maternidad" (152-157) abre nuevos horizontes para profundizar en el Misterio ${ }^{76}$.

$\square \quad M^{a}$ Clara Bingemer afirma que la progresiva emergencia de lo femenino va influyendo en todos las realidades. Nuestro Dios unitrino como Misterio que integra la pluralidad, la alteridad y la diferencia en la unidad, es capaz también de integrar lo masculino y lo femenino a luz de su fundamento que es Dios. "La teología trinitaria y el redescubrimiento de sus rasgos femeni-nos tiene -según procuramos mostrar aqui- fundamentos en la Sagrada Escritura y en la Tradición de la Iglesia. Por lo tanto, se inscribe en el hilo conductor del camino de un pueblo que tiene como constante la Alianza y la compañía de un Dios, que desea la liberación de toda forma de opresión. En la Iglesia de la América Latina actual, ..., el anuncio del Dios de la vida ... el misterio mayor del amor al cual nombramos Padre, Hijo y Espíritu Santo, el cual en su infinita misericordia, se revela tanto como fuerza engendradora y creadora, como entrañas que paren y son compasivas"77. Hans Urs von Balthasar en un breve artículo, sintéticamente, afirma que El Hijo hecho hombre aclara como tal (con su ser y su hacer) la esencia del Padre, ... así Jn 14,9 (el que me ha visto a mi ha visto al Padre) y explica lo más profundo de sí en el sufrimiento, en la cruz. El Espíritu Santo plenifica la primera y única explicación de Dios que los hombres no comprendemos. Solo podemos comprender porque Dios se explica. Además el misterio del hombre solo se esclarece desde el misterio del Verbo encarnado como afirma la GS $22^{78}$.

Annelise Meis afirma que para descubrir y acoger la revelación de lo femenino en su dimensión auténtica será necesario la combinación de todos los elementos valiosos que se han ido detectando: Así "la catolicidad se comprende ciertamente como aquella posibilidad única de 'existir lo uno en lo otro' y no tanto como contraposición dialéctica de elementos adversos ${ }^{\text {"79 }}$.

Cfr B. CASTILLA y CORTAZZAR, "El nombre propio del Espiritu Santo", Estudios Trinitarios 32 (1998) 115-166.

M.C.BINGEMER, 164 .

Cfr H.U. VON BALTHASAR, "Dios es su propio exégeta": Communio, Madrid 1 (1986), 7-12.

A. MEIS, 149. Se puede ver todo el articulo que en sintesis afirma:

a) "María es regalo de feminidad como expresión de una disposición creatural profunda para acoger la autodonación de Dlos que la transforma, de modo único, en "llena de gracia". I.../. Transformará el regalo de la feminidad, en cuanto "gracia" en."carisma". El ser femenino es un don que media entre Dios y los hombres y los hombres entre si", p. 153-154.

b) El ser femenino como libertad "significa 'autorrealizarse a partir de Otro', en el servicio, en el despojamiento total, p. 158. 


\section{EN CONCLUSIÓN:}

La autoconstitución gratuita a partir del Otro es un rasgo del rostro femenino de Dios.

Lo femenino se constituye por la gratuidad reciproca con el otro, con el mundo y la historia, y en tensión con la tendencia de "autofundarse a partir de sí mismo", y esto sin duda es una dimensión de lo divino ${ }^{80}$.

Hacer del Dios manifestado en Jesús el centro de nuestro ser, que su Espíritu nos anime, nos envuelva en velo de belleza, de bondad y de verdadero gozo $\sin$ fin.

ii Levantémonos y caminemos hacia la Casa del Padre Materno!!.

c) Lo femenino en su verdad profunda es que "la vida surge sólo a partir de la muerte en una entrega total, pues si el grano de trigo no cae en la tierra y muere, queda solo. Esta verdad, tan acentuada por Jesús, pero al mismo tiempo tan femenina, se constituye en punto culminante de la revelación del ser Maria mujer en relación con su Hijo y con los hijos en el Hijo", p. 161.

d) Lo femenino tiene su especificidad y ha de ocupar el lugar que le corresponde en su misión en la Iglesia, "según la voluntad de Jesús, y que no carece de tensiones por su forma paradójica, tal como se puede aprecia en Maria", p. 165.

e) Por fin María ilumina "la oblación total del amor, la fuerza que sabe resistir a los más grandes dolores, la fidelidad sin limites, la laboriosidad infatigable y la capacidad de conjugar la intuición penetrante con la palabra de apoyo y de estímulo" (RM 46), p. 168. 